\title{
RENDIMENTO DE GRÃOS E MASSA DE CEM SEMENTES DE CULTIVARES DE FEIJOEIRO CULTIVADOS SOB PALHADA DE LEGUMINOSAS EM CASA DE VEGETAÇÃO
}

\author{
Elaine Bahia Wutke (1) $^{(1)}$ \\ Roberto Tetsuo Tanaka ${ }^{(1,2)}$ \\ Hipólito A. Antonio Mascarenhas ${ }^{(1,2)}$
}

\section{RESUMO}

Objetivando-se a otimização da multiplicação de sementes genéticas do feijoeiro em condições controladas, realizou-se um estudo em casa de vegetação com irrigação automatizada, no Setor de Leguminosas do CEGRAFI do Instituto Agronômico - IAC, em Campinas, SP, de 12/12/2001 a 25/03/2002. Avaliou-se o efeito da utilização, em cobertura do solo, de palhada residual das leguminosas soja, soja-perene e labelabe e de um tratamento testemunha sem palhada no rendimento de grãos e na massa de cem sementes dos cultivares de feijoeiro: Carioca, IAC-Carioca e IAC-Carioca Aruã, cultivados em vasos com solo do tipo Latossolo Vermelho Escuro. Os tratamentos foram distribuídos em delineamento experimental inteiramente ao acaso, em esquema de parcelas subdivididas, com vinte e quatro repetições. Cada vaso com 3 plantas foi considerado uma repetição e os dados obtidos foram analisados pelo teste de Duncan a $5 \%$ de probabilidade. Obtevese aumento tanto no rendimento em grãos quanto na massa de sementes genéticas de cultivares de feijoeiro com a utilização de palhada, particularmente da soja e do labelabe.

Palavra-chave: Phaseolus vulgaris, cultivares, sementes, cobertura morta, adubação verde.

\footnotetext{
1 Instituto Agronômico-IAC, Centro de Análise e Pesquisa Tecnológica do Agronegócio de Grãos e Fibras, Av. Barão de Itapura, 1481, Caixa Postal 28, 13001-970, Campinas, SP.

2 Bolsista do CNPq.
} 


\section{YELD OF GRAINS AND WEIGHT OF A HUNDRED SEEDS OF COMMON BEANS CULTIVATED UNDER GREEN MANURE RESIDUES IN A GREENHOUSE}

\section{ABSTRACT}

An experiment was carried out under controlled conditions in a greenhouse of the Section of Leguminous Plants of CEGRAFI, Instituto Agronômico - IAC, from December 12/2001 to March 25/2002 in order to maximize the harvest of genetic seeds of common beans (Phaseolus vulgaris $\mathrm{L}$.). The objective was to evaluate the effects of the use of dry matter of green manure crops, such as soybean (Glycine max), perennial soybean (Glycine wightii) and Dolichos lablab and a treatment with no cover on the yields and seed mass of three cultivars of common bean: Carioca, IAC Carioca and IAC-Carioca Aruã, cultivated in pots containing a Haplortox soil. The experimental design was a split plot with 24 replications and 3 plants per pot, each pot represented a replication. Analysis of variance and Duncan's test at the $5 \%$ level where used to study the data. The results showed increase in seed yield as well as seed mass of common bean cultivars by using dry matter of green manure of soybeans and labelabe plants at the surface of the plots cultivated under green house conditions.

Key words: Phaseolus vulgaris, cultivars, seeds, dry matter, green manure residues.

\section{INTRODUÇÃO}

As leguminosas, tanto alimentícias como adubos verdes, vêm sendo estudadas no Instituto Agronômico (IAC) há várias décadas, envolvendo a manutenção de um banco de germoplasma da maior importância para a preservação das espécies, linhagens e cultivares introduzidos ou gerados pela instituição e, também, para um ativo intercâmbio estadual, nacional e internacional (Wutke et al, 2002).

A multiplicação de sementes genéticas em condições controladas é uma das relevantes etapas necessárias à manutenção de todo e qualquer 
banco de germoplasma de determinada espécie vegetal. Assim é que, há alguns anos, vem sendo realizado um trabalho em colaboração entre o Setor de Leguminosas do Instituto Agronômico - IAC e o Sistema de Produção de Sementes desta instituição, em Campinas, SP, para fins de produção de sementes genéticas de distintos cultivares de feijoeiro e sua posterior multiplicação em campos de produção de sementes tanto genéticas quanto básicas.

Considerando-se a relevância de tal atividade e objetivando a maximização dos rendimentos de sementes em condições controladas, realizou-se o presente estudo em casa de vegetação, com o objetivo de avaliar o efeito da utilização de palhada residual das leguminosas soja, soja-perene e labelabe, na superfície de vasos com solo, e de um tratamento sem palhada, no rendimento de grãos e na massa de cem sementes dos cultivares de feijoeiro Carioca, IAC-Carioca e IAC-Carioca Aruã.

\section{MATERIAL E MÉTODOS}

O presente estudo foi desenvolvido em casa de vegetação com irrigação localizada com um emissor por vaso, no Setor de Leguminosas do CEGRAFI deste IAC, em Campinas, SP, de 12/12/2001 a 25/03/2002, para avaliação do efeito da utilização de palhada residual das leguminosas soja, soja-perene e labelabe, na superfície de vasos com solo, e de um tratamento sem palhada, no rendimento de grãos e na massa de cem sementes dos cultivares de feijoeiro Carioca, IAC-Carioca e IAC-Carioca Aruã.

Utilizou-se palhada composta predominantemente por restos de vagens e hastes secas, como aproveitamento da trilhagem das referidas leguminosas. Ela foi distribuída em camada de cerca de $1 \mathrm{~cm}$ de espessura, sobre a superfície de amostra de Latossolo Vermelho Escuro, anteriormente corrigido para elevação da saturação por bases para 70\%, e contida em vasos com $5 \mathrm{~kg}$. Realizou-se adubação mineral apenas de manutenção, já que o nível de fertilidade estava alto, constando da aplicação de cerca de 2 gramas/vaso da fórmula 04-14-08 na semeadura, sem adubação nitrogenada em cobertura.

Utilizou-se delineamento experimental inteiramente ao acaso, em 
esquema de parcelas subdivididas, com vinte e quatro repetições. Cada vaso continha 3 plantas de feijão, sendo considerado como uma repetição. Incluiu-se ainda um tratamento testemunha, sem cobertura de palhada.

Realizaram-se duas pulverizações para controle de ácaro rajado e mosca branca e uma para controle da doença ferrugem.

A colheita foi manual, realizada, respectivamente, aos 97, 99 e 103 dias após a semeadura para os cultivares Carioca, IAC-Carioca e IAC-Carioca Aruã.

As plantas foram trilhadas individual e manualmente, sendo determinados o rendimento em grãos, com correção da umidade para $13 \%$, e a massa de cem sementes. Os dados obtidos foram submetidos à análise da variância e as médias comparadas pelo teste de Duncan a 5\% de probabilidade (Pimentel-Gomes, 1984).

\section{RESULTADOS E DISCUSSÃO}

Como o nível de fertilidade estava alto para todos os elementos, de acordo com os resultados obtidos nas análise química do solo contido nos vasos, esta condição não foi restritiva ao cultivo do feijoeiro.

Os dados de rendimento de grãos estão relacionados na Tabela 1 . Obtiveram-se diferenças significativas entre cultivares, tipos de palhada e na interação cultivar x palhada. Os valores de rendimento do cultivar

Tabela 1: Rendimento de grãos de cultivares de feijoeiro desenvolvidos sob palhada de leguminosas em casa de vegetação.

IAC,Campinas

\begin{tabular}{|c|c|c|c|c|}
\hline \multirow{2}{*}{$\begin{array}{l}\text { Tipo de } \\
\text { Palhada }\end{array}$} & \multicolumn{3}{|c|}{ Cultivares de Feijão } & \multirow[b]{2}{*}{ Média } \\
\hline & Carioca & IAC - Carioca & IAC - Carioca Aruã & \\
\hline & \multicolumn{4}{|c|}{ 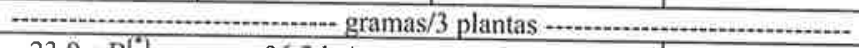 } \\
\hline Testemunha & $23,9 \mathrm{c} \mathrm{B}^{\left({ }^{\circ}\right)}$ & $36,3 \mathrm{bA}$ & $31,4 \mathrm{bA}$ & $30,5 \mathrm{~b}$ \\
\hline Soja & 36,7 a B & 49,3 a A & $29,4 \mathrm{bC}$ & $38,4 \mathrm{a}$ \\
\hline Soja Perene & $28,7 \mathrm{bc} \mathrm{A}$ & $28,1 \mathrm{cA}$ & $33,7 \mathrm{ab} \mathrm{A}$ & $30,1 \mathrm{~b}$ \\
\hline Labelabe & $34,4 \mathrm{ab} \mathrm{B}$ & $46,0 \mathrm{aA}$ & 39,0 a B & $39.8 \mathrm{a}$ \\
\hline Média & $30,9 \mathrm{~B}$ & $39,9 \mathrm{~A}$ & $33,4 \mathrm{~B}$ & $\cdots$ \\
\hline \multicolumn{5}{|c|}{ CV cultivar: $17,1 \%$; CV Palhada: $33,8 \%$} \\
\hline
\end{tabular}


IAC-Carioca foram significativamente superiores aos dos outros dois genótipos, entre os quais não houve diferenças. Utilizando-se palhada superficial de labelabe e de soja obtiveram-se rendimentos estatisticamente superiores e distintos dos observados com soja perene e com a testemunha sem palhada.

Analisando-se os resultados da interação, observa-se efeito positivo da palhada de labelabe para todos os três cultivares estudados, obtendo-se ganhos médios porcentuais de 43,9\%; 26,7\% e $24,2 \%$ em Carioca, IAC-Carioca e IAC-Carioca Aruã respectivamente. Com a palhada de soja também se observou ganho estatístico similar para Carioca e IAC-Carioca.

Isso está de acordo com informações relatadas em literatura compilada por Bulisani et al. (1987) e Wutke et al. (1998), mais especificamente sobre os efeitos benéficos da fitomassa de leguminosas no rendimento do feijoeiro, muito embora, em sua maioria, essa fitomassa tenha sido incorporada. Por outro lado, os dados obtidos não indicam efeito relevante da soja-perene, o que porém pode ser explicado pela utilização apenas dos restos das vagens como palhada, sendo que nos casos relatados na literatura, tem-se a utilização de toda a fitomassa aérea. Consequientemente, há maior rendimento de grãos por unidade de área, nessa condição específica de produção, com contribuição à multiplicação de sementes tanto do banco de germoplasma dessa espécie quanto de sementes genéticas.

Tabela 2: Massa de cem sementes de cultivares de feijoeiro desenvolvidos sob palhada de leguminosas em casa de vegetação IAC, Campinas, SP, 2001/2002.

\begin{tabular}{|c|c|c|c|c|}
\hline \multirow{2}{*}{$\begin{array}{l}\text { Tipo de } \\
\text { Palhada }\end{array}$} & \multicolumn{3}{|c|}{ Cultivares de Feijào } & \multirow{2}{*}{ Média } \\
\hline & Carioca & IAC - Carioca & IAC - Carioca Aruã & \\
\hline & \multicolumn{4}{|c|}{. } \\
\hline Testemunha & 25,8 bc B & $27,0 \mathrm{bA}$ & $23,1 \mathrm{~b} \mathrm{C}$ & $25,3 \mathrm{c}$ \\
\hline Soja & $26,2 \mathrm{~b} \mathrm{~B}$ & $29,6 \mathrm{aA}$ & 23,7 a C & $26,5 \mathrm{a}$ \\
\hline Soja Perene & $25,7 \mathrm{cA}$ & $25,5 \mathrm{c} \mathrm{A}$ & $23,3 \mathrm{ab} \mathrm{B}$ & $24,8 \mathrm{~d}$ \\
\hline Labelabe & 27,5 a A & $27,2 \mathrm{bA}$ & $23,3 \mathrm{ab} B$ & $26,0 \mathrm{~b}$ \\
\hline Média & $26,3 \mathrm{~B}$ & $27,3 \mathrm{~A}$ & $23,4 \mathrm{C}$ & $\cdots$ \\
\hline
\end{tabular}

Médias seguidas pelas mesmas letras minúsculas nas colunas e maiúsculas nas linhas não são diferentes entre si pelo teste de Duncan a $5 \%$ de probabilidade. 
Na Tabela 2 estão relacionados os dados referentes à massa de cem sementes. Também para esse parâmetro foram obtidas diferenças significativas entre cultivares, tipos de palhada e na interação cultivar $x$ palhada. Os valores observados para os cultivares foram superiores aos considerados característicos desses materiais, que são, em média, da ordem de $25 \mathrm{~g}, 23 \mathrm{~g}$ e $22 \mathrm{~g}$, respectivamente para Carioca, IAC-Carioca e IAC-Carioca Aruã (Almeida et al., 1971; Pompeu, 1987; Pompeu, 1996). Todos os valores de massa de sementes foram estatisticamente diferentes entre si, sendo significativamente superiores quando se utilizou a palhada superficial de soja, seguindo-se a de labelabe.

Analisando-se os resultados da interação nota-se efeito positivo da palhada de soja na massa de sementes dos cultivares IAC-Carioca e IAC-Carioca Aruã, com ganhos médios porcentuais respectivos da ordem $9,6 \%$ e $2,3 \%$ em relação à testemunha sem palhada. Para o cultivar Carioca tem-se um melhor resultado com a palhada de labebabe, com ganho médio de 6,6\% nesse parâmetro. Em todos os tratamentos com palhada os maiores resultados de massa de sementes foram obtidos com o cultivar IAC-Carioca enquanto que os menores em IAC-Carioca Aruã. Com palhada de soja-perene e de labelabe a massa de cem sementes do cultivar Carioca foi estatisticamente similar à do cultivar IAC-Carioca.

A produção de sementes maiores é agronomicamente mais interessante, pois, usualmente, obtêm-se plântulas mais vigorosas, conforme Arruda (1957).

Ainda, pode-se prever menor evaporação da água de irrigação, em função da palhada de recobrimento na superfície, o que se torna relevante devido à época de produção das sementes genéticas, a qual, neste caso, se estende de dezembro a março, período em que as temperaturas internas na casa de vegetação variaram entre 40 e $45^{\circ} \mathrm{C}$. Embora em condições de campo, e em situação de incorporação de fitomassa de adubos verdes, Almeida et al. (1971) obtiveram favorecimento da produtividade do feijoeiro, em estudos preliminares, em todos os tratamentos em que se associaram duas ou três das práticas agrícolas: massa vegetal, irrigação e adubação NPK. 


\section{CONCLUSÃO}

A utilização de palhada de leguminosas, particularmente de soja e de labelabe, na superfície do solo, em casa de vegetação, é viável para fins de obtenção de aumento tanto no rendimento em grãos quanto na massa de sementes genéticas de feijoeiro.

\section{AGRADECIMENTO}

Aos funcionários de apoio do Instituto Agronômicos, Paulo Eduardo Magalhães, Francisco Vidal Filho, Nair Antônia dos Santos e Luzia Fátima da Silva pela colaboração durante todas as fases da experimentação em casa de vegetação e no laboratório de sementes.

\section{REFERÊNCIAS BIBLIOGRÁFICAS}

ALMEIDA, L. D'A. de.; MIYASAKA, S.; IGUE, T.; ORTOLANI, A. A.; ALOISI SOBRINHO, J.; SORDI, G. de; ALVES, S., 1971. Efeitos, na Produção do Feijão "da sêca", da Irrigação, da Adubação Mineral e da Incorporação ao Solo de Massa Vegetal Semidecomposta de Crotalaria juncea L. Bragantia, 30(20):289304.

ALMEIDA, L. D'A. de; LEITÃO FILHO, H. F.; MIYASAKA, S., 1971. Características do Feijão Carioca, um Novo Cultivar. Bragantia, 30:33-38, (Nota, 7)

ARRUDA, H. V. de., 1957. Correlação Entre o Pêso da Planta e o das Sementes, em Variedades de Feijoeiros. Bragantia, 16(26)385388.

BULISANI, E. A.; COSTA, M. B. da C.; MIYASAKA, S.; CALEGARI, A.; WILDNER, L. do P.; AMADO, T. J. C.; MONDARDO, A., 1992. Adubação Verde nos Estados de São Paulo, Paraná, Santa Catarina e Rio Grande do Sul. In: COSTA, M. B. da C. (coord.) Adubação verde no sul do Brasil. Rio de Janeiro: AS-PTA, 1992. Parte II, p.59-81.

PIMENTEL-GOMES, F. P. A estatística Moderna na Pesquisa Agropecuária. Piracicaba: POTAFOS, 160p. 
POMPEU, A. S., 1987. Melhoramento do Feijoeiro. In: BULISANI, E. A. (coord.). Feijão: Fatores de Produção e Qualidade. Campinas, Fundação Cargill, p.1-28.

POMPEU, A. S., 1996. Cultivares de Feijoeiro: IAC-Carioca Aruã e IAC-Carioca Akytã. Campinas: Instituto Agronômico, (Folder). WUTKE, E.B.; FANCELLI, A.L.; PEREIRA, J.C.V.N.A.; AMBROSANO, G.M.B., 1998. Rendimento do Feijoeiro Irrigado em Rotação com Culturas Graníferas e Adubos Verdes. Bragantia, 57(2):325-338.

WUTKE, E.B.; MASCARENHAS, H. A. A.; BRAGA, N. R.; TANAKA, R. T.; MIRANDA, M.A.C. de; POMPEU, A. S.; AMBROSANO, E. J., 2001. Pesquisas sobre Leguminosas no Instituto Agronômico e sua Contribuição para o Desenvolvimento Agrícola Paulista. O Agronômico, 53(1):34-37. 